Mr J. Osborn was afraid that the Bill would open the door to commercial espionage, and moved an amendment to widen the clause covering secrecy of information. Mr Short said the intention of the amendment was simple, but it was unworkable. Once again the amendment was withdrawn, and finally the report stage was completed and the Bill was read for the third time.

\section{A Louder Voice for Technicians}

THE largest technicians' union in the world is in prospect with the recommendation by the executives of the AScW and ASSET that the two associations should amalgamate. The AScW is the Association of Scientific Workers, and ASSET is the Association of Supervisory Staffs, Executives and Technicians; on July 2 the two executives considered the report of a joint committee, and agreed unanimously that amalgamation would be in the best interests of their membership. Before the merging of the associations can go into effect, there must be a full ballot of the members, which will be preceded by a series of meetings at which the arguments can be put across. If the members agree with their executives, the association; could be merged by February 1968.

The reasons for the amalgamation are not hard to find. With a joint membership which the executives claim, perhaps optimistically, at 80,000 , the joint union will be both more powerful and more effectively organized than the two could hope to be alone. Not the least of its possessions will be the General Secretary of ASSET, Mr Clive Jenkins, who has been a thorn in the side of the British Government throughout the prices and wages freeze. Employers will have to face some tough battles if the merger goes through, but these will be as nothing compared with the situation if AScW and ASSET take their arguments to a logical conclusion and start negotiations towards a merger with DATA, the Draughtsmen's and Allied Technicians' Association. DATA has a membership of over 71,000 , and is recognized as one of the most determined unions in Britain-employers would probably prefer the term intransigent. A full scale merger of this sort could ultimately lead to a membership of 250,000 .

\section{Good Cheer for Neuro-biologists}

IT seems probable that neuro-biology will profit from the work of a sub-committee of the Science Research Council which has been making a survey of needs in this field in the past few months. One way and another, the sub-committee seems to have convinced itself that there are, in particular, shortages of neuro-anatomists and of biochemists wishing to pursue research in neurochemistry, and shortages of funds necessary for their support. One probable result is that the Biology Committee of the Science Research Council may commit itself, and the Science Research Council as well, to a deliberate policy of expansion in neurobiology, sometimes even going as far as to suggest particular research projects. Another approach will be to provide courses by means of which professional scientists can become skilled in these fields. In this spirit, Professor J. Z. Young at University College, London, is hoping to provide courses in neuro-anatomy at University College, London, lasting from three to twelve months if there is enough demand-and if the SRC will provide support. In much the same way, the SRC seems now to be at least half committed to a programme for the more generous support for animal behaviour - another of the four fields of research singled out for special study by the Biology and Biochemistry Committee.

These developments are potentially interesting as innovations of principle as well as for the practical benefits which they may bring. For one thing, these activities mark the continuing growth of the interest of the SRC in the biological sciences. For another, it may be an important precedent in the administration of British science that a public grant-giving agency should set out deliberately to stimulate the demand for grants in particular fields of study - this is entirely in line with the way that charitable foundations now seek to work, but public bodies have often been much more content to follow a passive policy. The interest of the SRC in neuro-biology will also raise again the question of how the Science Research Council should relate its work to that of the Medical Research Council, which supports research in neuro-biology. That question would be much easier to answer if the MRC were possessed of a more explicit strategy for the spending of money.

\section{A Committee for Hovercraft}

By the apparently immutable rule that every new task implies a new advisory committee, the National Physical Laboratory is to have a hovercraft committee. The committee will tell the NPL what research is needed to support the development of hovercraft, including hovertrains, and how much money will be needed to carry it through.

The first chairman of the committee will be $\mathrm{Mr}$ M. A. L. Banks, who has just retired as the Deputy Chairman of the British Petroleum Company, and the members of the committee will be nominated by all the interested parties, including the Ministry of Defence, the NRDC, the Ministry of Transport, and an organization representing the firms licensed to manufacture hovercraft. Already there is promise of further working parties, to look after marine hovercraft, tracked hovercraft, or, indeed, as the announcement puts it, "any other aspect of the subject where there is need".

\section{Road Research}

QuiTe suddenly, it seems, the Road Research Laboratory has become a vital part of the planning of the Ministry of Transport. The proposals on road pricing which the Minister, Mrs Barbara Castle, is studying will rely heavily on work done by the laboratory. The recent legislation which compels all new cars to have seat belts is also a result of the laboratory's work. The philosophy-an entirely sensible one-seems to be that it is more profitable to minimize injury when accidents do occur than to hope that by constant exhortation accidents can be banished altogether.

The report of the laboratory for 1965 and 1966 provides some examples of this approach. Collisions with conventional lamp standards produce severe damage, often almost cutting cars in half; but, by using a new type of break-away lamp standard, damage can be considerably reduced. Guard rails mounted along 